\title{
A bolsa permanência nas políticas de educação superior: assistência estudantil na UFMS
}

\author{
Carina Elisabeth Maciel ${ }^{*}$ \\ Felipe Vieira Gimenez ${ }^{* *}$
}

Jacira Helena do Valle Pereira Assis ${ }^{* * *}$

\section{Resumo}

O presente estudo tem como objetivo identificar a política de Assistência Estudantil posta em prática na Universidade Federal de Mato Grosso do Sul/UFMS, campus Campo Grande/MS, por meio de Programas de Apoio Pedagógico e Financeiro oferecido aos estudantes, haja vista que a "Bolsa Permanência" consiste em estratégia de estabilidade do aluno bolsista na referida instituição. A pesquisa é de caráter exploratório, bibliográfico e documental, apresentando como fontes relatórios e documentos institucionais. Para tanto, embasamo-nos nos seguintes aportes teóricos: Sguissardi (2014); Maciel (2015); Mancebo, Bittar e Chaves (2012); Hofling (2016) e Borsato (2015). São apresentados e analisados dados quantitativos e qualitativos. O texto é resultado de parte da pesquisa financiada por meio do Edital FUNDECT/CNPq N¹4/2014 - PPP - MS. As primeiras aproximações nos levaram a identificar que a universidade em questão possui programas de apoio pedagógico e financeiro, mas que nem todos os alunos/as atendem aos critérios de seletividade impostos por cada uma das áreas: saúde, alimentação, bolsas de monitoria, permanência e mobilidade estudantil. Ou seja, a universidade encontra-se dualizada entre seus projetos e ações, contemplando apenas parte desses estudantes. Conclui-se que a ação Bolsa Permanência sofreu alterações em seus critérios de seleção e há um índice alto de vagas ociosas, tornando necessária uma revisão na política de acompanhamento dos acadêmicos selecionados e não selecionados pela ação.

Palavras-chave: Educação superior. Permanência. Assistência estudantil.

\footnotetext{
* Doutora em Educação pela Universidade Federal de Santa Maria (UFMS). Professora da Faculdade de Educação da Universidade Federal de Mato Grosso do Sul (UFMS).

** Mestre em Educação pela Universidade Federal de Santa Maria (UFMS).

*** Doutora em Educação pela Universidade de São Paulo (USP). Professora da Faculdade de Educação da Universidade Federal de Mato Grosso do Sul (UFMS).
} 


\section{Apresentação}

O presente estudo visa à investigação da temática sobre a permanência de estudantes na educação superior, tomando como base material de análise a política de Assistência Estudantil da Universidade Federal de Mato Grosso do Sul (UFMS) ${ }^{1}$ - campus Campo Grande/MS. Nesse contexto, merece destaque as mudanças ocorridas no cenário político com relação aos programas, projetos e ações implementados a partir das últimas décadas referentes à permanência dos estudantes nesse nível de ensino $^{2}$, o que alterou significativamente a elaboração e materialização de políticas sociais de assistência estudantil na universidade pública. Entende-se por política social, conforme Vieira (2009, p. 142-143):

A política social consiste em estratégia governamental e normalmente se exibe em forma de relações jurídicas e políticas, não podendo ser compreendida por si mesma. Não se definindo a si, nem resultando apenas do desabrochar do espírito humano, a política social é uma maneira de expressar as relações sociais, cujas raízes se localizam no mundo da produção. [...] E não se põem como totalidades absolutas enquanto esferas mais amplas, com a denominação de política social ou, em outro caso, de política econômica. Muito menos se põem como totalidades absolutas enquanto esferas específicas, que levam o nome de política educacional, habitacional, de saúde, previdenciária ou assistencial.

Assim, as políticas sociais, comumente chamadas de políticas públicas, resumem-se a programas e tópicos dirigidos a determinados focos. São descontínuas, fragmentadas, incompletas e seletivas, apresentam uma atuação dispersa, sem planejamento, esbanjando esforços e recursos oferecidos pelo Estado, sem controle da sociedade.

Nessa perspectiva, para desenvolvermos o objetivo principal proposto para este estudo, buscamos identificar quais ações integram a assistência estudantil da UFMS para favorecer a permanência do estudante após seu ingresso no curso de graduação presencial. Para tanto, discute-se, no cenário atual da educação superior, a ampla modificação na trajetória acadêmica, dentro das Instituições de Educação Superior (IES), com relação ao acesso e à permanência, dos programas e ações que passaram a integrar a educação superior com vistas a reduzir os efeitos da desigualdade social na universidade e, por fim, a identificação da redução do papel do Estado e a consequente ampliação da esfera privada. 


\section{Políticas públicas, programas e ações na educação superior}

Ao se propor o estudo da permanência na educação superior, coloca-se uma primeira problemática: quais programas e ações foram implementados nos últimos anos, no contexto das universidades federais brasileiras, que correspondem às demandas de permanência na Educação Superior? Quais relações devem ser apontadas para se pensar políticas a partir de um programa ou ação?

Nesse entendimento, cabe compreender o que é programa, projeto e ação. Segundo Januzzi (2014, p. 35), “programa é um dos instrumentos de operacionalização da política e, especificamente, trata-se de um conjunto sistêmico de ações programadas e articuladas entre si, com objetivo de atender uma demanda pública específica, encampada na agenda de prioridades de políticas públicas do Estado ou governo".

A noção de projeto, assim como o termo plano, também possui um caráter de sistematização da ação futura e, nesse sentido, a definição de projeto traz consigo a ideia de lançar-se adiante, de algo a construir. Por um lado, a ideia de projeto pode estar vinculada à noção de detalhamento de uma determinada ação a ser desenvolvida a partir do plano elaborado. Nesse sentido, o projeto consistiria na sistematização de uma parte ou de uma atividade prevista no plano a ser implementado. (SILVA, 2015, p. 3).

Nesse contexto, a relação entre Estado e políticas sociais deve ser considerada, pois toda política é implementada em uma determinada sociedade em determinado período histórico.

Diante disso, é importante explicitar a diferença entre os termos Estado e Governo utilizados nesse texto. Estado é entendido como o conjunto de instituições permanentes - como órgãos legislativos, tribunais, exército e outras -, que não formam, necessariamente, um bloco monolítico, mas possibilitam a ação do governo; e Governo, como o conjunto de programas e projetos que uma parte da sociedade (políticos, técnicos, organismos da sociedade civil e outros) propõe para a sociedade como um todo, configurando-se como a orientação política de um determinado governo que assume e desempenha as funções de Estado por um determinado período (HOFLING, 2001).

Segundo Magalhães (2013), o Brasil iniciou a década de 1990 com um processo de reformas em todas as esferas da vida pública, no qual as políticas sociais e econômicas ficaram submetidas aos princípios do neoliberalismo. Destaca-se que a área educacional foi um dos setores mais diretamente influenciado pelas enormes transformações econômicas e sociais desse período, tornando-se alvo de 
reformas que a adequassem ao novo padrão de acumulação financeira determinado pelas políticas de cunho neoliberal.

De acordo com Júnior e Sguissardi (2012, p. 21-2), assiste-se no Brasil a uma lenta e profunda mudança na cultura institucional da universidade pública, resultado das opções político-econômicas deliberada e conscientemente assumidas pelos governos Fernando Henrique Cardoso - FHC (19952002), Luiz Inácio Lula da Silva (2003-2010) e Dilma Rousseff (2011-2014).

Quadro 1 - Programas do Governo Federal nas IES Públicas (2003 a 2014)

\begin{tabular}{|c|c|}
\hline \multicolumn{2}{|c|}{ Programas na Graduação- Inclusão, acesso e permanência (2003 a 2014) } \\
\hline Programa/Ano/Lei & Objetivo \\
\hline $\begin{array}{l}\text { Programa Universidade Para Todos (Prouni) - } \\
\text { Criado por meio da Medida Provisória } \mathrm{n}^{\mathbf{0}} 213 \text {, de } 10 \\
\text { de setembro de } 2004 \text {, convertida na Lei } \mathrm{n}^{\mathbf{0}} 11.096 \text {, } \\
\text { de } 23 \text { de novembro de } 2005 \text {. }\end{array}$ & $\begin{array}{l}\text { Tem como objetivo a concessão de bolsas de estudo integrais e } \\
\text { parciais em cursos de graduação em IES privadas, as quais } \\
\text { recebem, em contrapartida, isenção de impostos federais. }\end{array}$ \\
\hline $\begin{array}{l}\text { Financiamento ao Estudante do Ensino Superior - } \\
\text { (Fies) - Criado em } 1999 \text { por Medida Provisória, } \\
\text { posteriormente convertida na Lei } \mathrm{n}^{\circ} 10.260 \text {, de } 12 \\
\text { de julho de } 2001 \text {. }\end{array}$ & $\begin{array}{l}\text { Programa destinado a financiar, prioritariamente, o ensino } \\
\text { superior de estudantes matriculados em IES não gratuitas, com } \\
\text { avaliação positiva nos processos conduzidos pelo Ministério da } \\
\text { Educação (MEC). Trata-se do mais importante instrumento de } \\
\text { financiamento estudantil atualmente existente. }\end{array}$ \\
\hline $\begin{array}{l}\text { Sistema de Seleção Unificada (Sisu) - } \\
\text { Implementado a partir de } 2009 \text {, mas instituído em } \\
\text { janeiro de } 2010 \text {. }\end{array}$ & $\begin{array}{l}\text { O processo seletivo unificado, implementado a } \mathrm{p} \\
\text { tem por diretriz a democratização do acesso às va } \\
\text { pelas instituições públicas e gratuitas de educação } \mathrm{s}\end{array}$ \\
\hline a de Bolsa Permanência (PBP) - 2013. & $\begin{array}{l}\text { É uma ação do Governo Federal de concessão de auxílio } \\
\text { financeiro a estudantes matriculados em instituições federais de } \\
\text { ensino superior em situação de vulnerabilidade socioeconômica e } \\
\text { para estudantes indígenas e quilombolas. }\end{array}$ \\
\hline $\begin{array}{l}\text { Acessibilidade na Educação Superior (Programa } \\
\text { Incluir) }-2005 \text {. }\end{array}$ & $\begin{array}{l}\text { Propõe ações que garantem o } \\
\text { deficiência às instituições federais }\end{array}$ \\
\hline $\begin{array}{l}\text { Programa Nacional de Assistência Estudantil } \\
\text { (Pnaes) - Decreto } \mathrm{n}^{\circ} 7.234 \text {, de } 19 \text { de julho de } 2010 \text {. }\end{array}$ & $\begin{array}{l}\text { O objetivo é viabilizar a igualdade de oportunidades entre todos } \\
\text { os estudantes e contribuir para o seu sucesso acadêmico, a partir } \\
\text { de medidas que buscam combater a repetência e evasão. }\end{array}$ \\
\hline $\begin{array}{l}\text { Programa Nacional de Assistência Estudantil para } \\
\text { as Instituições de ensino superior Públicas Estaduais } \\
\text { (Pnaest) - Portaria Normativa } \mathrm{n}^{\circ} 25 \text {, de } 28 \text { de } \\
\text { dezembro de } 2010 .\end{array}$ & $\begin{array}{l}\text { Visa apoiar financeiramente ações de assistência estudantil } \\
\text { desenvolvidas pelas universidades e centros universitários } \\
\text { estaduais públicos e gratuitos participantes do Sisu nas seguintes } \\
\text { áreas: moradia estudantil; alimentação; transporte; assistência à } \\
\text { saúde; inclusão digital; cultura; esporte; creche; apoio } \\
\text { pedagógico; acesso, participação e aprendizagem de estudantes } \\
\text { com deficiência, transtornos globais do desenvolvimento, altas } \\
\text { habilidades e superdotação. }\end{array}$ \\
\hline $\begin{array}{l}\text { Programa Milton Santos de Acesso ao Ensino } \\
\text { Superior (Promisaes) }-2005 \text {. }\end{array}$ & $\begin{array}{l}\text { Integra, simultaneamente, duas políticas da SESu: a } \\
\text { internacionalização e a permanência na educação superior. Trata- } \\
\text { se de iniciativa voltada para estudantes oriundos de países com os } \\
\text { quais mantém acordos - em especial os africanos - nas áreas de } \\
\text { educação e cultura. }\end{array}$ \\
\hline $\begin{array}{l}\text { Lei de Cotas - Lei n }{ }^{\circ} 12.711 \text {, de } 29 \text { de agosto de } \\
2012 .\end{array}$ & $\begin{array}{l}\text { Ivas são políticas adotadas para promover maior } \\
\text { so à educação, rompendo a herança de exclusão } \\
\text { se perpetua na sociedade brasileira. }\end{array}$ \\
\hline
\end{tabular}


Fonte: Brasil/MEC/SESu (2015).

Concomitantemente, ocorreu a emergência de programas com forte mudança institucional. No Quadro 1 identifica-se, nessa perspectiva, os programas que tiveram forte mudança institucional nas IES em sua forma de atendimento e inclusão social, com destaque para inclusão, acesso e permanência vigentes no período de 2003 a 2014.

Pode-se compreender que os programas (isto é, as chamadas políticas de Estado) que se referem à Educação Superior foram regulamentados no governo Lula (2003-2010). No entanto, há duas exceções: o Fies, criado em 1999, mas instituído por meio de lei no ano de 2001, e a Lei de Cotas (2012), criada no governo Dilma; ambos visam, em seus objetivos, o acesso, a inclusão e a permanência estudantil.

As políticas de Estado, podem ser definidas:

[...] como sendo mais duradouras, mas principalmente porque seriam imunes aos interesses partidários ou particularistas e fruto do debate, supostamente democrático, quando da sua tradução em leis, programas de caráter universal, etc. (SGUISSARDI, 2014, p. 13).

Nesse sentido, nos últimos anos, o governo brasileiro vem implementando políticas visando ao acesso à educação superior, a começar pela nova forma de ingresso nas universidades públicas do país pelo já conhecido Sisu. A entrada no ensino superior, antes realizada, na maioria das universidades públicas, na forma de vestibular, foi substituída pelo Exame Nacional do Ensino Médio (Enem), que anteriormente possibilitava ao estudante o ingresso nas universidades particulares através da concessão de bolsas de estudos (JÚNIOR; SGUISSARDI, 2012, p. 21-2).

O Enem tem como um dos seus objetivos democratizar o acesso às vagas federais na educação superior. A partir de 2010, efetiva-se como único meio de acesso à universidade pública, embora o Estado não tenha deixado de conceder bolsas de estudos por meio de outro programa, o Prouni, que se destina $^{3}$ à concessão de bolsas de estudo integrais e bolsas de estudo parciais de $50 \%$ (cinquenta por cento) ou de $25 \%$ (vinte e cinco por cento) para estudantes de cursos de graduação e sequenciais de formação específica em instituições privadas de ensino superior, com ou sem fins lucrativos (BRASIL, 2005). Além dos recursos públicos destinados para a iniciativa privada, o Prouni prevê, ainda, a isenção dos impostos para a instituição que aderir ao programa.

Com relação à permanência dos estudantes no contexto histórico das universidades federais, notam-se as iniciativas do Fórum Nacional de Pró-Reitores de Assuntos Comunitários e Estudantis (Fonaprace), que teve início em 1994 e realizou um levantamento amostral do perfil socioeconômico dos estudantes de graduação das IFES, na perspectiva de apresentar dados que possibilitassem construir 
uma política de assistência em que fosse assegurado não só o acesso como também a permanência dos estudantes nas universidades.

Em 1997, num processo de aprofundamento em relação ao levantamento amostral do perfil socioeconômico realizado em 1994, foi apresentado à Associação Nacional dos Dirigentes das Instituições Federais de Ensino Superior (Andifes) ${ }^{4}$ e ao MEC o resultado da $1^{\text {a }}$ Pesquisa do Perfil Socioeconômico e Cultural dos Estudantes de Graduação das IFES Brasileiras (FONAPRACE, 2011), por meio da qual foi possível elaborar o Plano Nacional de Assistência (BRASIL, 2007). As universidades participantes, à época, de posse dos dados, tiveram condições de formular suas políticas locais.

No relatório da primeira pesquisa, o Fonaprace apresentou de forma clara o seu posicionamento sobre a necessidade de uma política pública para a assistência estudantil universitária:

O processo de democratização no sistema educacional brasileiro, particularmente nas universidades públicas, passa necessariamente pela incorporação de estudantes oriundos de famílias de baixa renda. Não basta, entretanto, assegurar-lhes o acesso: é preciso considerar que o compromisso efetivo do estado com a democratização do ensino superior pressupõe a criação de condições concretas de permanência de todos os estudantes na universidade, até a conclusão do curso escolhido, através da formulação de programas que busquem atenuar os efeitos das desigualdades existentes, provocadas pelas condições da estrutura social e econômica. (FONAPRACE, 1997 apud ANDIFES, 1997, p. 1).

Conclui-se que a questão da permanência relaciona-se ao perfil familiar do estudante, ao perfil socioeconômico, à integração social e ao sucesso escolar nos vários níveis da educação básica, desde a educação infantil até a educação superior. Notam-se, nesse contexto, mudanças institucionais educacionais que apresentam como base supostas necessidades de desenvolvimento do país e não necessariamente dos estudantes universitários, discussão sobre a política de assistência ao estudante que se pretende avançar a partir do segundo momento do presente artigo.

\section{A política de assistência estudantil na UFMS}

Neste segundo momento, cabe problematizarmos sobre: quais são os programas de permanência oferecidos pela UFMS? A quem se destinam? Qual é o órgão responsável na UFMS? Quais elementos podem ser apontados para a permanência no campus?

As ações de Assistência Estudantil na UFMS, campus Campo Grande/MS, são administradas pela Pró-Reitoria de Extensão, Cultura e Assuntos Estudantis (Preae), por meio da Coordenadoria de Assuntos Estudantis. Essa coordenadoria é composta por quatro divisões: Divisão de Apoio e 
Assistência Acadêmica (Diaa), Divisão de Orientação e Informação (Dioi), Divisão de Acessibilidade e Políticas Afirmativas (Diaf) e Divisão de Monitoramento da Política de Assistência Estudantil (Dipe). As competências e atribuições de cada um desses setores são disciplinadas pela Resolução do Conselho Universitário (Coun) no 36, de 16 de abril de 2013 (UFMS, 2013). Nos campus, as atividades de orientação, execução e acompanhamento das ações de Assistência Estudantil são de responsabilidade da Comissão Permanente de Apoio e Assistência Acadêmica (CPAC) e são regulamentadas pela Resolução Coun nº 10, de 24 de abril de 2009 (UFMS, 2009).

Atualmente, as ações que compreendem a Assistência Estudantil da UFMS são: Auxílio Alimentação ${ }^{5}$; Auxílio Emergencial ${ }^{6}$; Atendimento Psicoeducacional ${ }^{7}$; Bolsa Permanência do MEC $^{8}$; Bolsa Permanência ${ }^{9}$; Suporte Instrumental/Kit ${ }^{10}$; Incentivo à participação em eventos ${ }^{11}$; Restaurante Universitário (RU) - Cidade Universitária ${ }^{12}$ e Passe estudantil - Cidade Universitária. A Divisão de Apoio e Assistência Acadêmica é responsável pelo Auxílio Alimentação, Auxílio Emergencial, RU Cidade Universitária, Incentivo à participação em eventos, Suporte Instrumental/Kit e Passe estudantil - Cidade Universitária. A Divisão de Acessibilidade e Ações Afirmativas é responsável pela ação Bolsa Permanência do MEC e Atendimento Psicoeducacional.

No âmbito da permanência, a UFMS define políticas explicitamente para este fim apenas no Plano de Desenvolvimento Institucional (PDI) 2010-2014, por meio da proposição dos programas de Apoio Pedagógico e Financeiro, que incluem as ações de "Estímulos à permanência".

Os Programas de Apoio Pedagógico e Financeiro abrangem:

a) Programa de Apoio ao Estudante: bolsa permanência, auxílio-alimentação, inclusão digital, brinquedoteca, incentivo à participação em eventos, nivelamento, suporte instrumental, recepção aos calouros, inclusão às línguas estrangeiras, suporte médico e odontológico, incentivo a participação em fóruns e eventos relacionados à assistência estudantil, apoio a eventos do movimento estudantil e auxílio financeiro ao estudante;

b) Programa Qualidade de Vida;

c) Programa de Orientação Profissional;

d) Programa Acessibilidade. (UFMS, 2011b, p. 82).

As ações dos referidos programas ampliam o envolvimento dos estudantes nas atividades acadêmicas e são destacadas na avaliação do PDI 2010-2014.

No Gráfico 1, apresenta-se o desenvolvimento do programa de monitoria, sob a responsabilidade da Pró-Reitoria de Ensino de Graduação (Preg), por meio do número de bolsistas e de bolsas pagas entre 2010 e 2013, referentes ao primeiro e segundo semestres do corrente ano: 


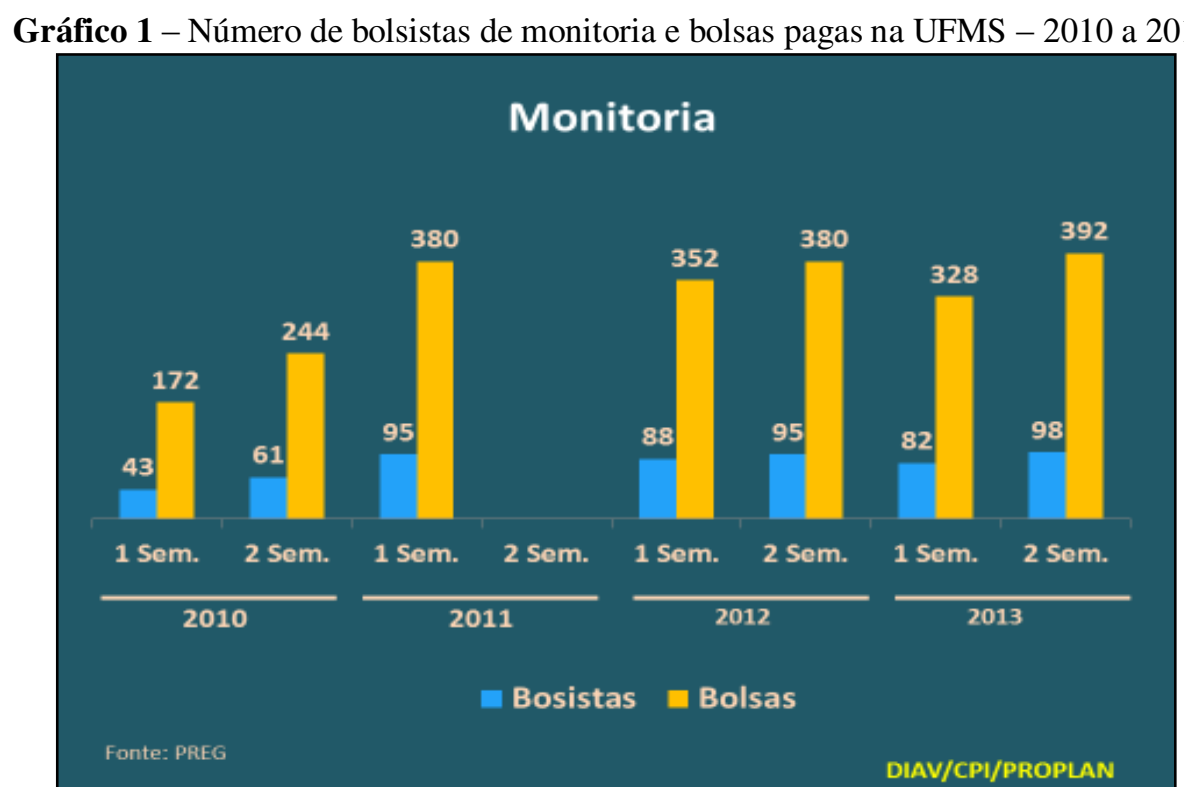

Fonte: UFMS/DIAV/CPI/Proplan (2014b).

No Gráfico 2, observa-se a concessão do Auxílio Alimentação, por número de bolsas concedidas e alunos beneficiados, havendo um crescimento nos anos de 2011 e 2012, queda em 2013 e novo crescimento em 2014. Os dados particularizados explicam esta queda, em face da reativação do restaurante universitário na sede, no segundo semestre de 2012. Observa-se que a maior parte das bolsas destina-se ao campus do interior do estado (MACIEL et al., 2015):

Gráfico 2 - Número bolsas concedidas e alunos atendidos pelo Auxílio Alimentação na UFMS - 2010 a 2014

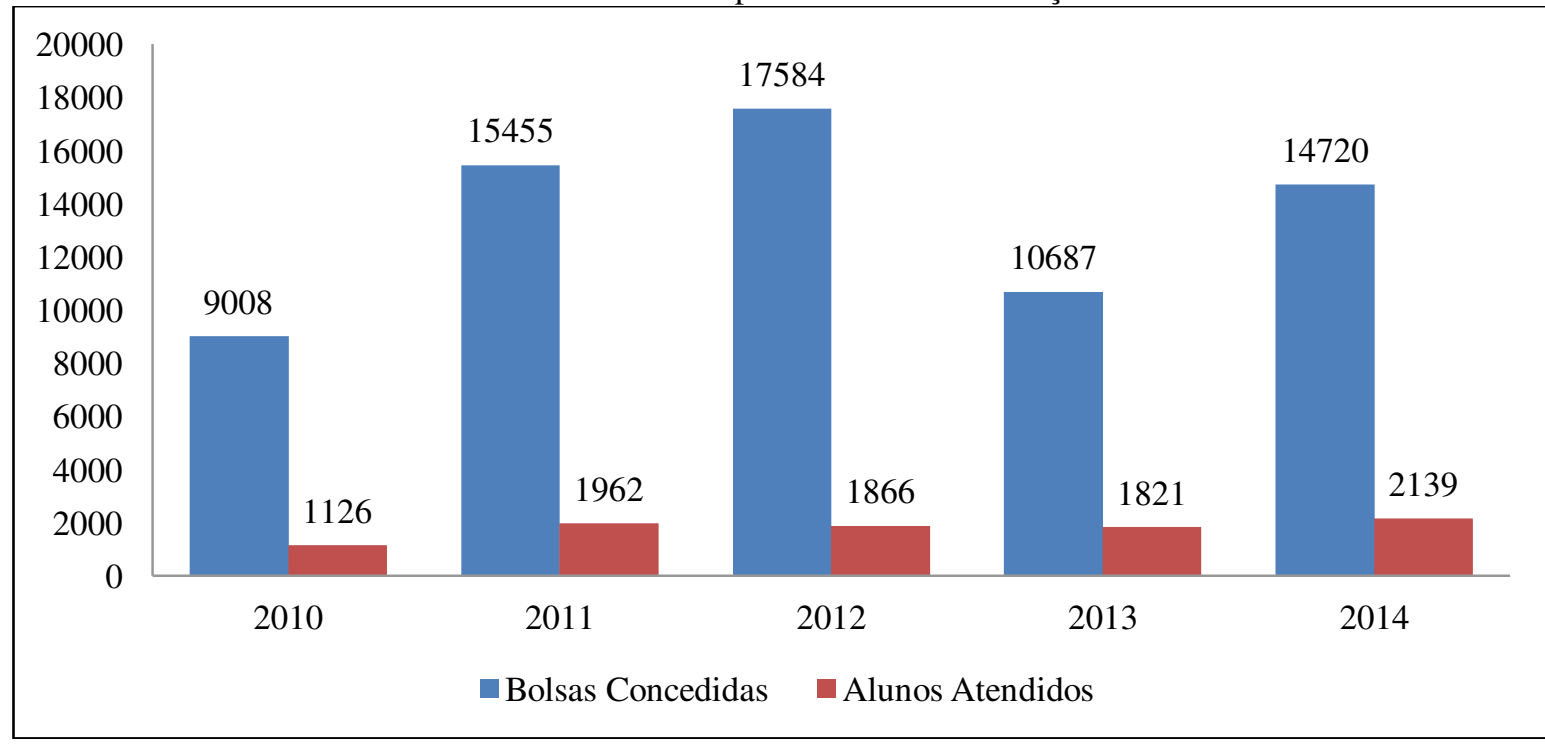

Fonte: UFMS/DIAV/CPI/Proplan (2015b, p. 54). 
No Gráfico 3, consta o desenvolvimento do Programa Bolsa Permanência, por bolsa concedida e alunos atendidos. Novamente, a particularização dos dados indica o predomínio das bolsas concedidas aos alunos do campus do interior do estado:

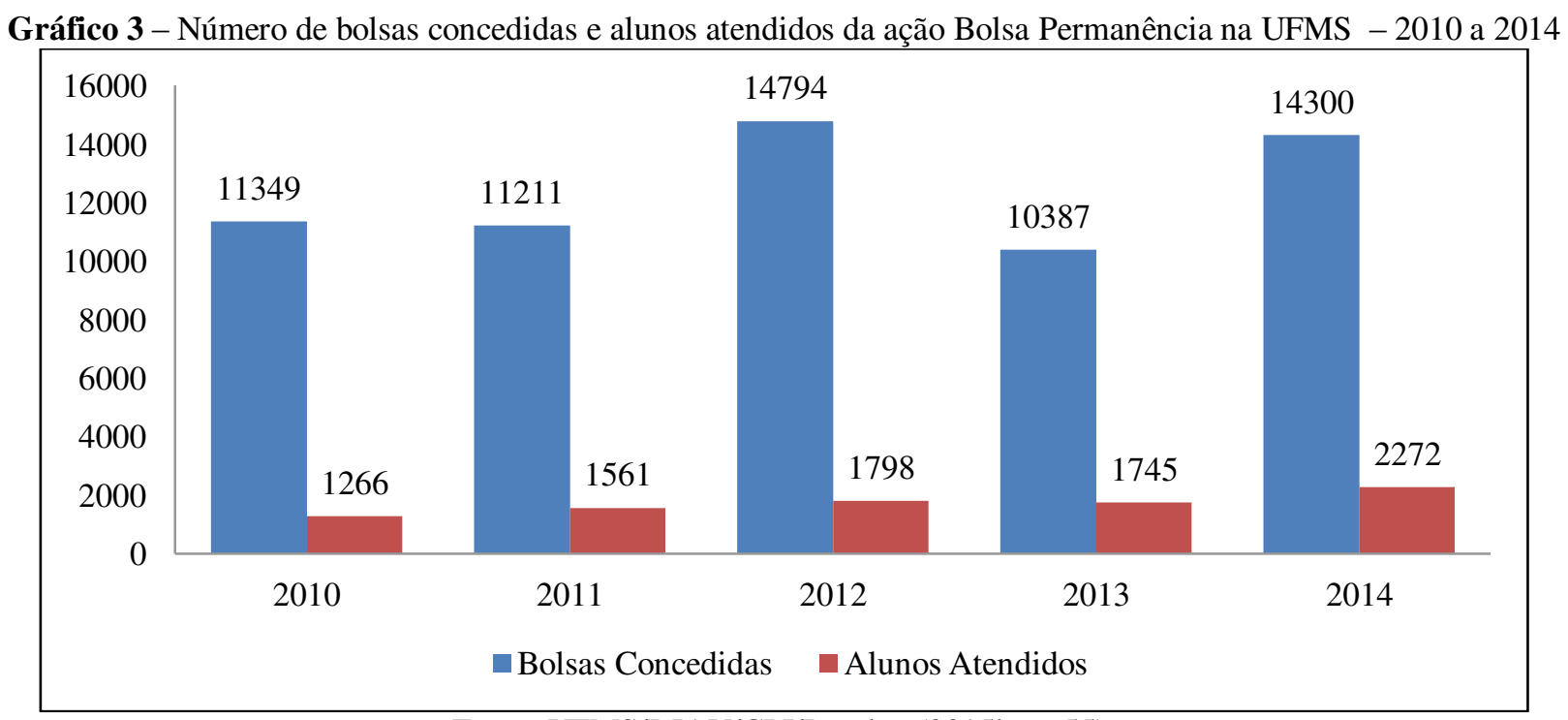

Fonte: UFMS/DIAV/CPI/Proplan (2015b, p. 55).

O número de acadêmicos atendidos se refere ao estudante bolsista. No relatório de gestão, ano base 2013, consta o número de bolsas concedidas, que é a soma das vezes que o estudante as recebeu. Tendo em vista que um estudante pode receber até onze bolsas ao ano, os dados apontam um número maior bolsas de concedidas do que de alunos atendidos.

A Assistência à Saúde, embora conte com profissionais próprios para este fim, também está vinculada ao ensino, por meio das práticas de ensino e estágios dos cursos voltados aos serviços de saúde. O número médio de alunos atendidos nos últimos cinco anos é de 785 estudantes (setecentos e oitenta e cinco), o que, em face da média de ingressantes e matriculados, cerca de 14 mil estudantes, contempla um pouco mais de 5\% (MACIEL et al., 2015). 


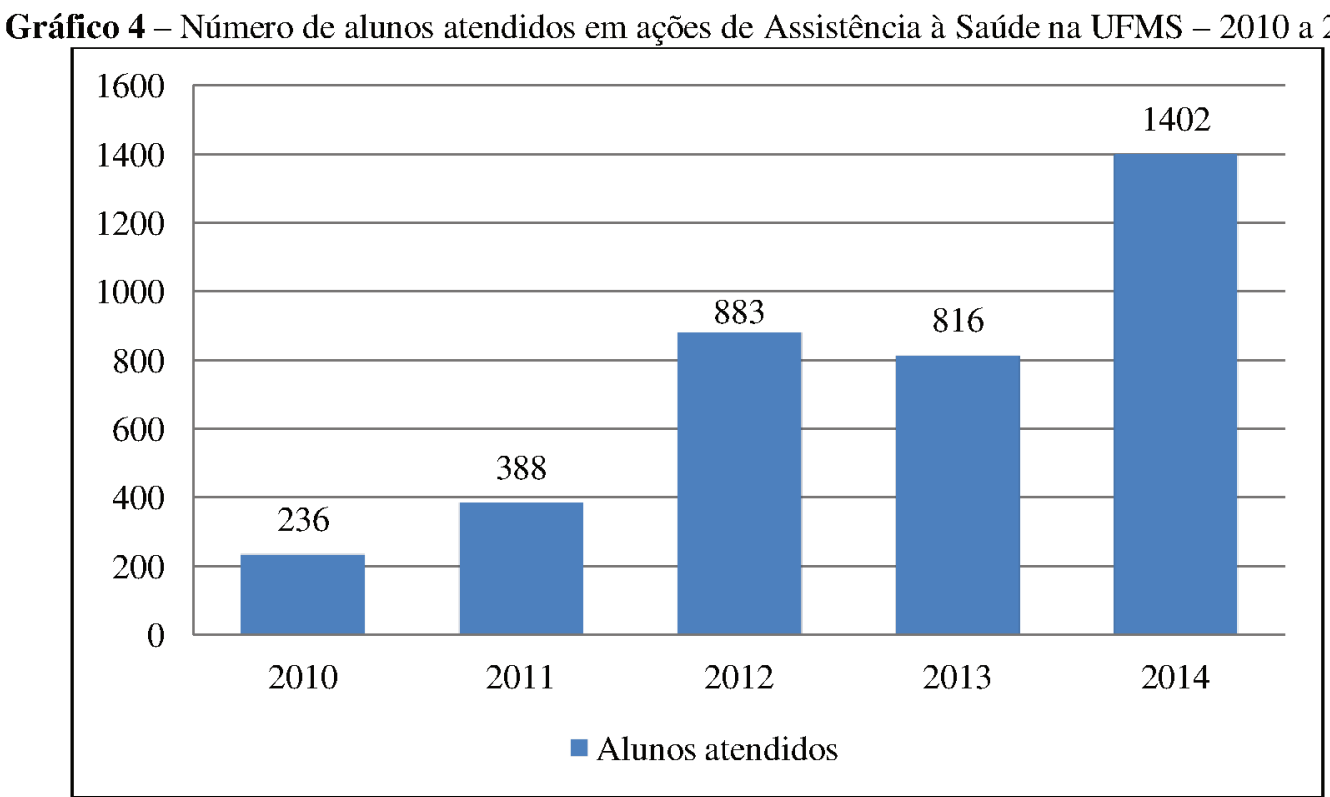

Fonte: UFMS/DIAV/CPI/Proplan (2015b, p. 56).

No PDI de 2010 a 2014, há uma marca nova, que é o processo de internacionalização, com o intercâmbio de docentes e pesquisadores, bem como a mobilidade estudantil entre instituições nacionais e internacionais. No caso dos estudantes, a adesão da UFMS ao programa "Ciência sem fronteiras" trouxe novas possibilidades de mobilidade estudantil, bem como os acordos de cooperação celebrados com as seguintes instituições:

- StaatlicheHochschule fur Gestaltung Karlsruhe - Alemanha;

- Universidad Autônoma Gabriel René Moreno - Bolívia;

- Universidade de Salamanca - Espanha;

- Texas A\&M - College of Vetinary - Estados Unidos;

- Universidade de Washington - Estados Unidos;

- Kochi University - Japão;

- Instituto Politécnico de Setúbal - Portugal;

- Instituto Superior Técnico - Portugal;

- Universidade de Algarve - Portugal;

- Universidade de Aveiro - Portugal; Universidade do Porto - Portugal.

- State University of New York (Estados Unidos)

- Universidade de Coimbra (Portugal)

- Universidade Nacional da Patagônia San Juan (Argentina). (UFMS, 2013, p. 23).

No Gráfico 5, aponta-se o número de estudantes em mobilidade estudantil a partir de 2011: 
Gráfico 5 - Número de alunos em mobilidade estudantil na UFMS - 2011 a 2013

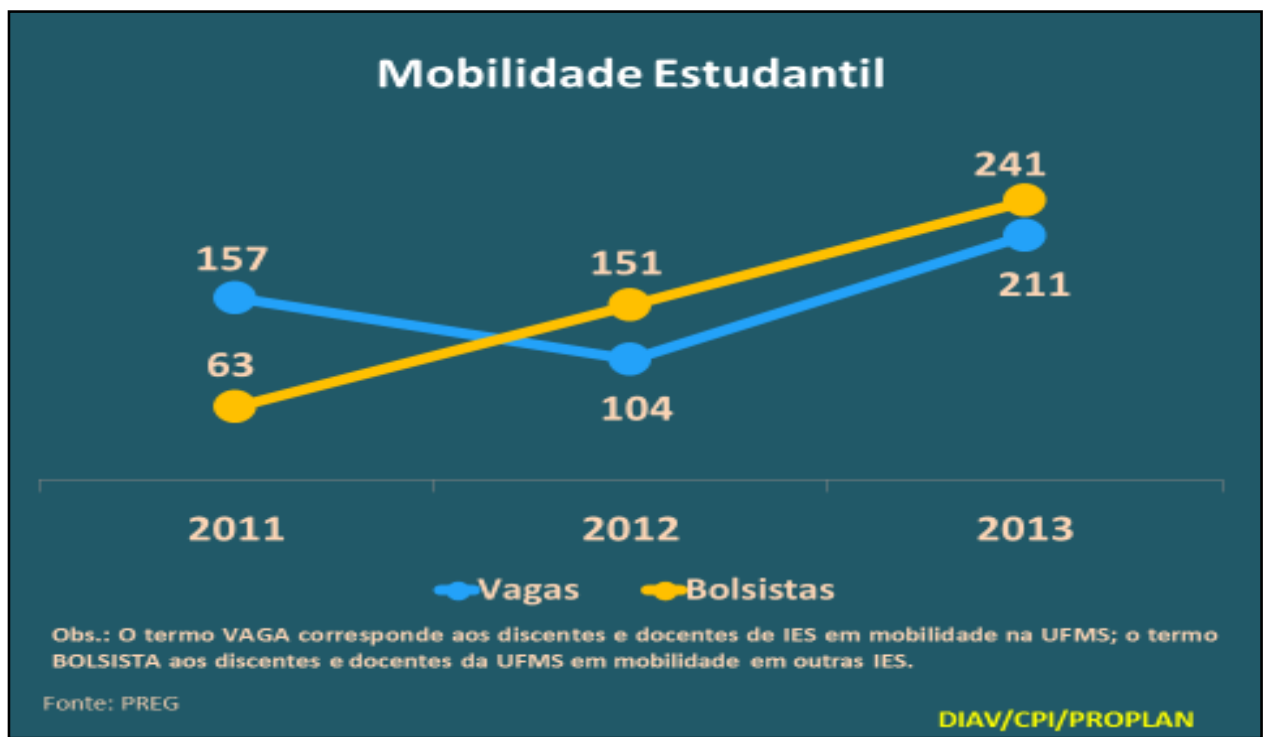

Fonte: UFMS/DIAV/CPI/Proplan (2014b).

Sobre a mobilidade estudantil, em consulta ao site da instituição, consta que é uma forma de os estudantes da UFMS cursarem um ou dois semestres dos seus cursos em outras IES, no Brasil ou no exterior, na forma de intercâmbio. As condições e critérios para o estudante participar da Mobilidade Acadêmica Nacional consistem em ter cumprido $20 \%$ da carga horária do curso de origem e apresentar, no máximo, duas reprovações nos dois semestres anteriores ao pedido de mobilidade.

Os dados relativos ao período de 2000 a 2013 apontam para ações institucionais sistemáticas e consistentes, no âmbito do planejamento, da gestão e de resultados, quanto à ampliação do acesso de estudantes, por meio da expansão de cursos, vagas, inscritos, ingressos, matrículas e da infraestrutura física da UFMS. As ações voltadas à permanência são mais recentes, articuladas a programas e ações com objetivos já determinados no Plano Plurianual do Estado Brasileiro, que tem a UFMS como uma das unidades executoras (MACIEL et al., 2015).

Vale observar ainda, tendo como base dados estatísticos e quantificáveis, que as políticas de permanências apresentam outros condicionantes sociais, pois os acadêmicos que ingressam na universidade precisam também ter acesso aos programas. No entanto nota-se que a universidade possui um programa de Apoio Pedagógico e Financeiro, mas nem todos os(as) alunos(as) são atendidos(as), devido à seletividade de critérios estabelecida por cada uma dessas áreas, desde a saúde, alimentação, bolsas de monitoria, permanência e mobilidade estudantil. Percebe-se, assim, uma universidade dualizada entre seus projetos e ações, contemplando partes desses estudantes. No seguinte tópico, nos 
aprofundaremos na análise dos dados obtidos sobre a ação Bolsa Permanência e os alunos atendidos pela Assistência Estudantil.

\section{Bolsa permanência na UFMS: novas configurações, velhos desafios}

Neste terceiro momento, propõe-se discutir a bolsa permanência em âmbito local e, para tanto, coloca-se outros questionamentos: o que subjaz na UFMS com relação às ações da política de Assistência ao Estudante como estratégia de permanência no campus? De que forma é realizada a seleção dos estudantes?

Nesse sentido, a permanência está condicionada a outros fatores e condicionantes externos e internos que são inerentes ao contexto do estudante. Segundo Maciel, Silva e Veloso (2015, p. 265) “[...] cumpre assinalar o entendimento expresso em documentos nacionais de que a permanência do estudante na educação superior associa-se a investimentos na assistência estudantil”.

Nesse contexto, sabemos que cada universidade pública federal possui e integra os programas do MEC, que, na maioria das vezes, não levam em consideração os reais direitos e necessidades do seu público, ou seja, os estudantes. Sob essa ótica,

[...] todas as universidades e instituições de Ensino Superior, mesmo que inseridas em países com economias distintas e mesmo sendo portadoras de histórias e "identidades" bastante diferenciadas, foram afetadas, de forma mais ou menos intensa, nas últimas décadas, pelas novas demandas da economia global, pelos novos papéis atribuídos ao Estado, e pelas "recomendações" embutidas em relatórios, documentos e empréstimos financeiros de organismos multilaterais a serviços dos Estados centrais. (MANCEBO; BITTAR; CHAVES, 2012, p. 14).

Assim, vivenciam-se momentos delicados na educação básica e superior, em razão dessa relação imposta pelo neoliberalismo no âmbito da educação, uma relação de mercado que não deixa de ser hegemônica e deve ser analisada a partir das relações existentes entre o Estado e sua construção histórica.

Dessa forma, a concepção de permanência deve ser entendida de uma maneira mais ampla, que não se restringe apenas ao atendimento aos mais vulneráveis. Segundo Silva e Veloso (2010, p. 222):

A permanência dá sentido ao acesso, configurando a continuidade da trajetória de formação; a expansão tem relação (e impacto) com o acesso, na proporção do crescimento quantitativo (instituições, vagas, matrículas, docentes, financiamento) e das suas características (ensino público/gratuito, organização acadêmica, curso, avaliação/qualidade). De igual forma, poder-se-ia mencionar outros fenômenos distintos, mas a ele articulados, como financiamento e evasão. Tais questões 
convergem para a afirmativa de que o acesso não comporta uma explicação isolada ou descontextualizada.

Nesse viés, Cordeiro (2015, p. 834) entende a permanência como uma política institucional, um compromisso que a instituição assume para evitar/diminuir a evasão de estudantes, que precisa ir além da mera preocupação com números e criar um espaço de relações na universidade que leve em conta a diversidade e a diferença que constituem o perfil dos/as estudantes, de modo a desempenhar sua função social de promoção e exercício da cidadania.

A universidade pública expandiu-se no período compreendido entre 1930 e 1970, mas, desse período até os dias atuais, as políticas mercantilistas ${ }^{13}$ do ensino superior fortaleceram o setor privado, que hoje detém aproximadamente $90 \%$ das instituições e 70\% do total de matrículas. (ZAGO, 2006, p. 228).

As reformas do Governo Federal nestes últimos anos afetaram todos os níveis de ensino, e a educação superior é reflexo da política de mercantilização.

A crise de hegemonia expressa-se, por exemplo, pela incapacidade - pelo não incremento de seus recursos financeiros - de as instituições públicas expandirem consideravelmente suas atividades para atender à enorme demanda pelo ensino superior, havendo então uma grande expansão do sistema privado. A crise de legitimidade apresenta-se quando as instituições não conseguem dar respostas rápidas às demandas que lhe são dirigidas pelos diversos segmentos da sociedade, sobretudo do setor produtivo. A crise institucional instala-se quando surgem críticas em relação à eficiência, custos e competitividade, no contexto do "quase-mercado". Como solução para esses problemas, as propostas são de que lhes seja "imposta" uma gestão empresarial, nos moldes de uma empresa privada, o que, em tese, as tornaria mais eficientes e produtivas. (OLIVEIRA, 2006, p. 11).

Destarte, explicam Amaral e Chaves (2013, p. 42) que a política privatista adotada pelo Governo Federal foi reforçada por meio da Lei $n^{\circ}$. 5.172, de 25 de outubro de 1966, que instituiu o Código Tributário Nacional, e permanece até os dias atuais, tendo se concretizado por meio de inúmeras ações que favorecem o setor privado, em especial as que concedem isenções ${ }^{14}$ fiscais a esse setor. Como resultado dessa política, as instituições de ensino sem fins lucrativos têm sido beneficiadas com uma série de incentivos fiscais de renúncia tributária, seja pela isenção total de impostos e contribuições ou pela redução de alíquotas.

Na UFMS a ação Bolsa Permanência foi criada em substituição à Bolsa de Trabalho Interno, por meio da Resolução do Conselho Diretor (CD) $\mathrm{n}^{\circ} 31$, de 8 de julho de 2008. Sua finalidade é contribuir financeiramente com o acadêmico, de forma que este possa custear suas despesas pessoais de alimentação e moradia. Os valores estabelecidos eram de 59\% do salário mínimo para os acadêmicos 
da Cidade Universitária e 72,6\% do salário mínimo para o demais campus. Essa diferença era justificada pela existência de transporte coletivo 100\% gratuito em Campo Grande (BORSATO, 2015).

Neste contexto, a UFMS busca redimensionar as ações desenvolvidas, implementando programas existentes e implantando novas ações a partir das áreas estratégicas e linhas temáticas definidas no Plano Nacional de Apoio ao Estudante (PNAES), possibilitando o envolvimento dos acadêmicos beneficiários dos programas de assistência estudantil, em atividades relacionadas à sua área de formação na interface com o ensino, a pesquisa e a extensão (UFMS, 2011, p. 83).

Em 2010, o Programa Bolsa Permanência sofreu alterações por meio da Resolução do Coun $n^{\circ}$ 7, de 23 de fevereiro de 2010. As alterações preveem que os acadêmicos de outras instituições, em mobilidade estudantil na UFMS, estejam incluídos no Programa de Bolsa da instituição de origem; também incluiu o PNAES como fonte dos recursos financeiros para custear a ação; e, por último, houve alterações no processo seletivo, entre elas a inclusão do requisito de ausência de vínculo empregatício para que o estudante participe das ações (BORSATO, 2015).

Diante dessa proposta, a concepção sobre o acesso e a permanência na UFMS pode ser identificada no artigo 77 do Estatuto da instituição, no qual se faz menção às atribuições da assistência ao corpo discente, quais sejam: a) promoções de natureza cultural, esportiva e recreativa; b) programas de bolsas de trabalho, extensão, monitoria, iniciação cientifica e estágio; e c) orientação psicopedagógica e profissional. A assistência estudantil se consolida com a implantação do Programa Nacional de Assistência Estudantil/PNAES/Sisu/MEC ${ }^{15}$.

O Programa Nacional de Assistência Estudantil, instituído pelo Decreto no 7.234, de 19 de julho de 2010, executado no âmbito do MEC, tem como finalidade ampliar as condições de permanência dos jovens na educação superior pública federal ${ }^{16}$.

Segundo estudos de Borsato (2015), a Assistência Estudantil, no período anterior ao PNAES, ficou marcada por ações pontuais, muitas das quais, para sua realização, dependiam das parcerias estabelecidas com fundações de apoio ou empresas, como é o caso da Bolsa Alimentação e do Auxílio Moradia. Em virtude dos escassos recursos e, em consequência disso, da oferta de poucas vagas, as ações eram focalizadas em atender o público com menor renda familiar, e era nisso que se concentrava o trabalho dos poucos Assistentes Sociais: fazer a seleção dos acadêmicos.

Com a chegada dos recursos do PNAES, novas ações foram organizadas nos campus da UFMS, entre estas a ação denominada Bolsa Permanência. No regulamento da ação dessa bolsa, Resolução $n^{\circ}$ 64, de 27 de novembro de 2012, são esclarecidas a sua natureza e finalidade ${ }^{17}$. 
Em 2012, ocorreram mais duas alterações na Resolução da Bolsa Permanência. A primeira, Resolução do Coun $n^{\circ}$ 9, de 2 março de 2012, alterou o valor das bolsas, as quais passaram a ter como referência os valores das bolsas correspondentes pagas pelas agências oficiais de fomento à pesquisa no país, qual seja, o valor de 400 reais.

Diante dessa proposta, qual tem sido a estratégia principal adotada pela UFMS no seu contexto local como estratégia para a permanência dos estudantes? Para a execução dos objetivos estabelecidos, o documento propõe a atuação em quatro áreas estratégicas, que seriam desenvolvidas por meio de programas e projetos fundamentados em metas quantificáveis: permanência; desempenho acadêmico; cultura, lazer e esporte; e assuntos da juventude (BORSATO, 2015).

Nesse contexto, apontaremos a ação Bolsa Permanência na UFMS (sede), cidade universitária, em Campo Grande/MS, que tem sua natureza e finalidade expressas na Resolução no 7 , de 6 de fevereiro de 2015.

No artigo $2^{\circ}$ da Resolução, fica entendido que a ação Bolsa Permanência integra a Política de Assistência Estudantil da UFMS e destina-se aos acadêmicos em situação de vulnerabilidade socioeconômica regularmente matriculados em curso de graduação da Fundação Universidade Federal de Mato Grosso do Sul na modalidade presencial. Sobre o financiamento: "Art. 33- Os recursos financeiros utilizados para a execução da ação estão assegurados no Programa Nacional de Assistência Estudantil (Pnaes).” (UFMS, 2015a).

Sobre o objetivo da ação:

Art. $5^{\circ}[\ldots]$ tem por objetivo auxiliar financeiramente o acadêmico em situação de vulnerabilidade socioeconômica, de forma a garantir a sua permanência na Universidade e contribuir para sua formação integral, buscando reduzir os índices de retenção e evasão decorrentes de dificuldades de ordem socioeconômica. (UFMS, 2015a, p. 4).

É uma ação vinculada à Política de Assistência Estudantil, sendo oportuno mostrar quantos estudantes são beneficiados por ela, tanto no campus local quanto nos campus do interior, e inferir análises decorrentes dessa política, que foi regulamentada em 2009 pelo MEC, mas que já existia dentro do campus em outro formato, configurada como "bolsa-trabalho".

Encontram-se na Lei $n^{\circ} 12.155$, de 23 de dezembro de 2009, e no Decreto $n^{\circ} 7.416$, de 30 de dezembro de 2010, os critérios para recebimento da bolsa. Destaca-se no artigo $3^{\circ}$ que o candidato às bolsas de permanência deverá atender aos critérios postos pela instituição, a saber:

Art. $3^{\circ}$ Aplicam-se ao candidato às bolsas de permanência e de extensão os seguintes requisitos, sem prejuízo de outros específicos fixados pela instituição:

I - estar regularmente matriculado em curso de graduação; 
II - apresentar indicadores satisfatórios de desempenho acadêmico, definidos pela instituição;

III - ser aprovado em processo de seleção, que deve considerar critérios de vulnerabilidade social e econômica, no caso da bolsa permanência;

IV - não receber qualquer outra bolsa paga por programas oficiais; e

$\mathrm{V}$ - apresentar tempo disponível para dedicar às atividades previstas no edital de seleção, quando a modalidade exigir. (BRASIL, 2010, grifo nosso).

Nota-se que ambas as modalidades mencionadas, Bolsa Permanência e Bolsa Extensão, têm objetivos distintos na IES: enquanto uma utiliza como critério de seleção a vulnerabilidade social e econômica para "garantir" acesso e permanência, a outra modalidade de extensão possui outro sentido e significado para as IES, pois atribui às atividades de extensão suma importância.

No caso da UFMS, a seleção objetiva inserir nas ações da assistência estudantil os estudantes regularmente matriculados em cursos de graduação presencial, com vistas à promoção de sua permanência, ação esta descrita a seguir.

Bolsa Permanência: consiste de um repasse financeiro no valor de $\mathrm{R} \$ 400,00$ ao acadêmico em situação de vulnerabilidade socioeconômica, de forma a contribuir com as suas despesas básicas durante o período de graduação na universidade. $\mathrm{O}$ acadêmico beneficiado deverá cumprir carga horária de 12 horas semanais em atividades de ensino, pesquisa ou extensão (UFMS, 2015a).

Dos requisitos para participação, o estudante deverá atender os seguintes: estar regularmente matriculado em curso de graduação presencial e possuir renda per capita inferior a um salário mínimo e meio. A graduação cursada pelo candidato deverá ser a primeira.

Por ter sido selecionado como bolsista, o estudante preenche o termo de compromisso, concordando com as normas fixadas no Regulamento da ação Bolsa Permanência, aprovada pela Resolução Coun nº 7/2015.

Os seguintes compromissos são assumidos pelo bolsista:

Manter-me regularmente matriculado na Instituição, garantindo aprovação em, no mínimo, 70\% das disciplinas matriculadas, durante a vigência do benefício;

Cumprir carga horária de 12 horas semanais, em atividades pré-definidas com meu (minha) Tutor (a) e por ele (a) supervisionado, sem que as atividades da Bolsa Permanência gerem qualquer tipo de vínculo empregatício com a UFMS;

Entregar rigorosamente no prazo estipulado o Relatório Mensal de Atividades da Bolsa Permanência, no mês subsequente às atividades, ciente de que o atraso implicará o não pagamento do valor da bolsa e de que, a não entrega de Relatórios por três meses consecutivos implicará no cancelamento da participação na Ação Bolsa Permanência; Não acumular, simultaneamente, qualquer tipo de bolsa remunerada, mantida pela UFMS ou qualquer outro órgão de fomento;

Manter atualizadas as minhas informações de conta corrente, informando qualquer alteração à DIAA/CAE[Coordenadoria de Assuntos Estudantis]/Preae ou CPAC de meu Campus; 
Informar à DIAA/CAE/Preae ou CPAC de meu Campus a necessidade de qualquer afastamento das aulas ou das atividades da Bolsa Permanência;

Participar das reuniões de bolsistas promovidas pela DIAA/CAE/Preae ou pela CPAC de meu Campus;

Informar à DIAA/CAE/Preae ou CPAC se houver troca de Tutor (a) e/ou de atividade, elaborando um novo Termo de Compromisso.

Informar à DIAA/CAE/Preae ou CPAC se houver alteração que supere a renda per capita de até um salário mínimo e meio vigente.

(UFMS, 2015a).

Os compromissos assumidos por parte do bolsista são muitos. Merecem destaque a vinculação da contrapartida trabalhista de 12 horas semanais, a aprovação em 70\% das disciplinas matriculadas e a impossibilidade de o estudante acumular esta bolsa com outras pagas por órgãos de fomento interno e externo. Assim, se o valor pago ao estudante não for suficiente, ele não poderá concorrer a outro processo seletivo, salvo para troca de modalidade, como o Programa Institucional de Bolsas de Iniciação Científica (Pibic), Pibic-AF [Ações Afirmativas], Programa Institucional de Bolsas de Iniciação à Docência (Pibid), Programa de Educação Tutorial (PET), Programa Institucional de Bolsas de Iniciação em Desenvolvimento Tecnológico e Inovação (Pibit) e bolsas de extensão.

Em relação à ação Moradia Estudantil no campus da UFMS, pode-se inferir que esta foi substituída pela ação Bolsa Permanência. Além disso, houve um aumento considerável dos recursos, das bolsas ofertadas e dos(as) acadêmicos(as) atendidos(as) pela ação desde 2008 até 2013.

Quadro 2 - Ações de Assistência Estudantil desenvolvidas de 2008 a 2013 na UFMS

\begin{tabular}{|c|c|c|c|c|c|c|c|c|}
\hline $\begin{array}{c}\text { Linhas de } \\
\text { acão PNAES }\end{array}$ & \multicolumn{2}{|c|}{ Ações de Assistência estudantil da UFMS } & 2008 & 2009 & 2010 & 2011 & 2012 & 2013 \\
\hline $\begin{array}{l}\text { Moradia } \\
\text { Estudantil }\end{array}$ & Bolsa Permanência & $\mathrm{N}^{\mathrm{o}}$ de acadêmicos atendidos & 249 & 879 & 1.266 & 1.561 & 1.798 & 1.745 \\
\hline
\end{tabular}

Fonte: Quadro elaborado por Borsato (2015) com base nos dados disponíveis nos Relatórios de Gestão de 2008 a 2013 da UMFS.

Na UFMS, campus Campo Grande, o número de acadêmicos atendidos em 2013 com a Bolsa Permanência foi de 425 (quatrocentos e vinte e cinco) estudantes (UFMS/DIAV/CPI/PROPLAN, 2014b). 


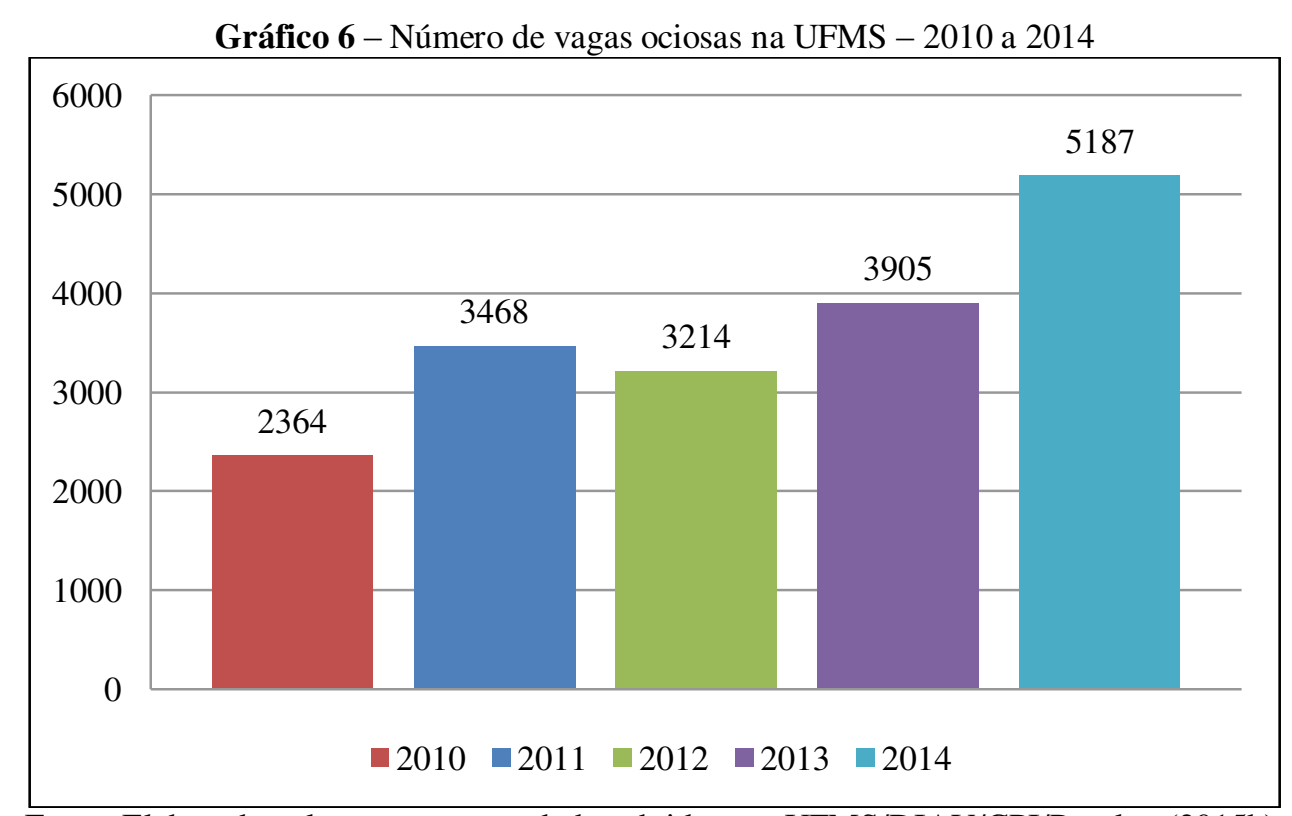

Fonte: Elaborado pelos autores com dados obtidos em UFMS/DIAV/CPI/Proplan (2015b).

Os dados do Gráfico 6 trazem o número de vagas ociosas na UFMS até 2014: 5.187 (cinco mil, cento e oitenta e sete), ou seja, um número que vem crescendo desde 2010, período em que se somavam 2.364 (duas mil, trezentas e sessenta e quatro) vagas ociosas. O número de matrículas em cursos presenciais em 2013 foi de 14.571 (quatorze mil, quinhentos e setenta e um) e o número de concluintes em cursos presenciais foi de 1.736 (mil, setecentos e trinta e seis), conforme demonstrado no Gráfico 7:

Gráfico 7 - Número de concluintes nos cursos de graduação presencial e a distância na Universidade Federal de Mato Grosso do Sul - 2000 a 2012

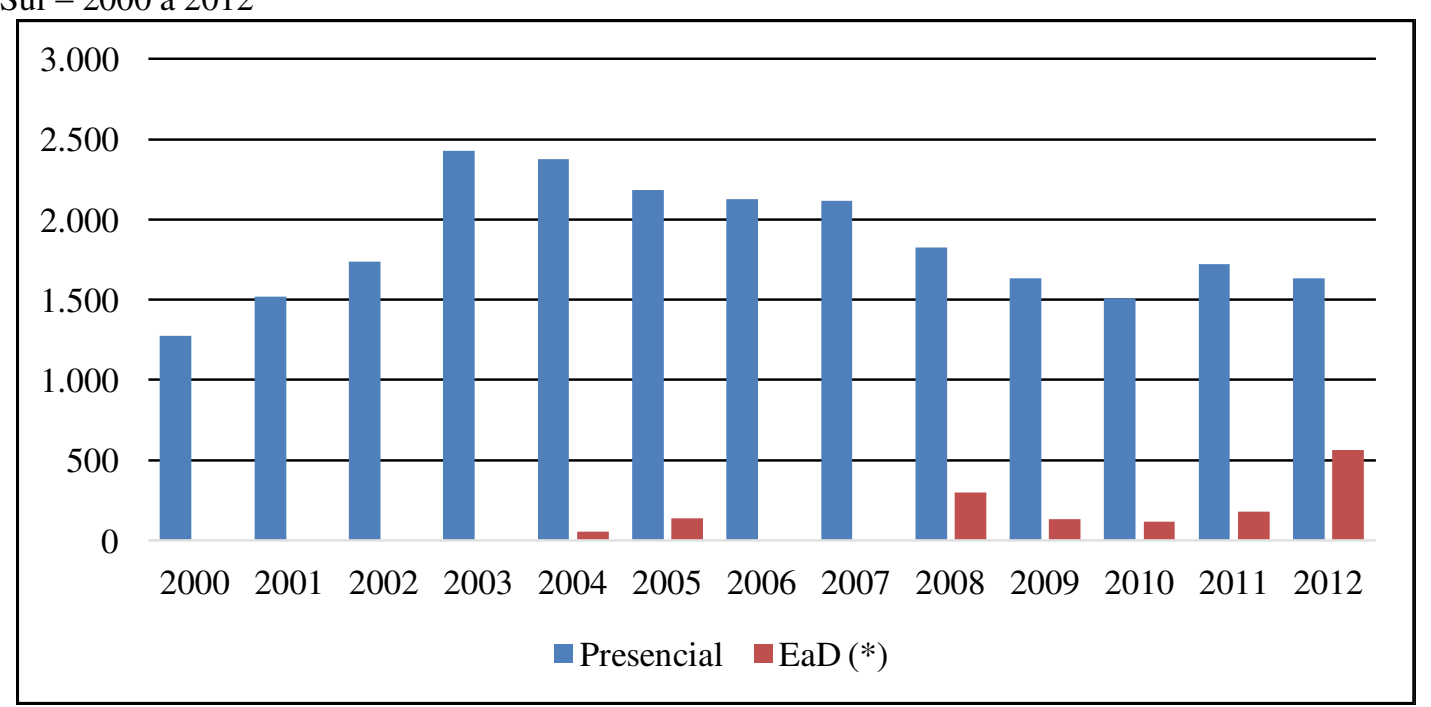

Fonte: Elaborado por Maciel (2015) a partir de dados da Sinopse Estatística da Educação Superior (INEP, 2000-2012). 
Segundo dados da Assistência Estudantil da UFMS, 31 acadêmicos concluíram o curso e participavam da ação Bolsa Permanência em 2013. Em 2014, foram 25, e em 2015/2 os prováveis concluintes serão 27 acadêmicos(as).

A pesquisa de Santana (2015) teve como objetivo analisar os resultados obtidos por meio dos formulários preenchidos pelos estudantes atendidos pela ação Bolsa Permanência na UFMS. Sobre a avaliação final da ação, foi identificado nos questionários, a partir das respostas à questão que versava sobre considerarem ou não que a Bolsa propicia a permanência e conclusão do curso, que, dos 34 estudantes, 29 responderam "Sim" e cinco responderam "Sim, parcialmente". Um estudante de Administração alegou que o "valor é muito baixo", já outro acadêmico, de Zootecnia, opina que "a conclusão do curso depende do aluno querer”; o terceiro, Bacharel em Química, descreve que "o tempo de pagamento é muito curto", e outros dois não opinaram. Segundo as respostas dos alunos, a ação cumpre seu papel (SANTANA, 2015, p. 11).

Infere-se que o número de concluintes apresenta-se abaixo do esperado, em comparação com a infraestrutura de uma universidade pública e gratuita, isto é, levando-se em consideração o número de vagas ofertadas a cada ano em relação às suas taxas de conclusão de curso, há um número considerável de vagas ociosas, como mostrado no Gráfico 6, fazendo-se necessária uma política de acompanhamento de todos os acadêmicos de graduação presencial, não apenas dos que são atendidos pela ação Bolsa Permanência.

Percebe-se como são necessárias mais ações referentes à Assistência Estudantil, à permanência desses estudantes na universidade e à efetiva conclusão do curso que considerem as especificidades dos estudantes atendidos. Como não há dados sobre os reais motivos da não conclusão do curso, pois a ação acompanha apenas os acadêmicos que o concluem, e devido ao fato do alcance deste artigo ser limitado pelas informações disponibilizadas, entendemos que se faz necessária a realização de novas investigações, que apontem os motivos que levam os acadêmicos a não permanecerem na instituição ou a trocarem de curso.

\section{Considerações finais}

As aproximações nos levaram a identificar que a permanência tem relação com os objetivos da política de assistência ao estudante na universidade, sendo ela voltada para inclusão social e de direito social. 
Segundo Maciel et al. (2015, p. 272), avançamos nas conquistas e ganhos sociais, mas a trajetória estudantil e seus desdobramentos ao longo da história têm contribuído para o debate em torno de um discurso de inclusão, expansão e permanência. "E o reconhecimento tímido do Estado, configurando uma agenda amparada na ideia de concessão ou doação”.

Nesse sentido, Amaral (2003) aponta que as instituições públicas, no novo formato de mercado, passam a atuar como um híbrido público-privado. No que se refere ao financiamento, apesar de continuar recebendo recursos do Fundo Público, esses são cada vez menores. Isso obriga as instituições a procurar fontes alternativas de recursos financeiros, seja pela prestação de serviços à população, oferecendo cursos de especialização e extensão, consultorias, assessorias etc., seja pela cobrança de taxas, matrículas, serviços de laboratórios e outros.

Vale observar que as políticas sociais de assistência aos estudantes ganham novos contornos e são afetadas pela lógica do financiamento e pelas relações entre educação, Estado e sociedade. Percebese que os problemas e fatores com relação à permanência na UFMS ultrapassam questões financeiras.

A permanência dá sentido ao acesso, configurando a continuidade da trajetória de formação; a expansão tem relação (e impacto no) com o acesso, na proporção do crescimento quantitativo (instituições, vagas, matrículas, docentes, financiamento) e das suas características (ensino público/gratuito, organização acadêmica, curso, avaliação/qualidade). De igual forma, poder-se-ia mencionar outros fenômenos distintos, mas a ele articulados, como financiamento e evasão. Tais questões convergem para a afirmativa de que o acesso não comporta uma explicação isolada ou descontextualizada. (SILVA; VELOSO, 2010, p. 222).

Notou-se que, com relação às políticas de permanência, os investimentos e os objetivos da proposta para o público-alvo, que são os estudantes de graduação, têm sido financiados a partir do PNAES, com o pagamento de bolsas e auxílios financeiros.

Conclui-se que ação Bolsa Permanência na UFMS sofre seus reajustes financeiros e estruturais, mostrando-se frágil diante de outras problemáticas que atingem a educação superior e perpassam a esfera federal até tingir a local, afetando as políticas de permanência existentes. Com isso, deixa de atingir totalmente o seu objetivo, embora se revele um importante mecanismo estratégico, como apontado na pesquisa de conclusão do curso, para a permanência daqueles que assim sobrevivem ao sistema do capital, permeado nesse campo por conflitos e interesses que demarcam o terreno das políticas de permanência na universidade contemporânea.

\section{Notas}


${ }^{1}$ A Fundação Universidade Federal de Mato Grosso do Sul, instituída pela Lei n ${ }^{\circ} 6.674$, de 5 de julho de 1979 , com sede e foro na cidade de Campo Grande, Estado de Mato Grosso do Sul, é uma entidade de ensino superior, de natureza multicampus, vinculada ao Ministério da Educação, com personalidade jurídica de direito público, gozando da autonomia didático-científica, administrativa, disciplinar e de gestão financeira e patrimonial, respeitando o princípio da indissociabilidade entre ensino, pesquisa e extensão.

${ }^{2}$ Ver Lei de Diretrizes e Bases da Educação Nacional (LDB), Lei nº 9.394, de 20 de dezembro de 1996. Título V: dispõe sobre os níveis e das modalidades de Educação e Ensino. Art. 21. A educação escolar compõe-se de: I educação básica, formada pela educação infantil, ensino fundamental e ensino médio; II - educação superior.

3 Extraído do Artigo $1^{\mathrm{o}}$ da Lei $\mathrm{n}^{\mathrm{o}} 11.096$, de 13 de janeiro de 2005 . Disponível em: <http://www.planalto.gov.br/ccivil_03/_ato2004-2006/2005/lei/L11096.htm>. Acesso em: 22 jan. 2016.

4 A Associação Nacional dos Dirigentes das Instituições Federais de Ensino Superior (Andifes), criada em 23 de maio de 1989, é a representante oficial das universidades federais na interlocução com o Governo Federal, com as associações de professores, de técnico-administrativos, de estudantes e com a sociedade em geral. Disponível em: <http://www.andifes.org.br/institucional/a-andifes/>. Acesso em: 22 jan. 2016.

5 É um auxílio financeiro destinado a acadêmicos matriculados em um dos cursos de graduação presencial nos campus da UFMS onde não exista Restaurante Universitário.

${ }^{6}$ É um repasse financeiro correspondente ao valor vigente da Bolsa Permanência da UFMS.

${ }^{7}$ É um atendimento oferecido por pedagogos e psicólogos a acadêmicos com dificuldades emocionais, transtorno global do desenvolvimento e/ou deficientes físicos, intelectuais, auditivos e visuais que estejam com dificuldades no processo de aprendizagem.

${ }^{8}$ É uma ação do Governo Federal na forma de concessão de auxílio financeiro a estudantes matriculados em instituições federais de ensino superior em situação de vulnerabilidade socioeconômica e a estudantes indígenas e quilombolas. O recurso é pago diretamente ao estudante de graduação por meio de um cartão de benefício.

${ }^{9}$ É um repasse financeiro ao acadêmico em situação de vulnerabilidade socioeconômica, de forma a contribuir com as suas despesas básicas durante o período de graduação na universidade.

${ }^{10}$ Consiste no empréstimo de um kit com materiais e instrumentos de alto custo, indispensáveis para a realização de alguns cursos de graduação, destinados aos estudantes em vulnerabilidade socioeconômica. Cursos atendidos pela ação: Artes visuais, Arquitetura e Urbanismo, Enfermagem (Cidade Universitária), Engenharia Civil, Engenharia Elétrica, Medicina e Música.

${ }^{11}$ É um auxílio financeiro aos acadêmicos em vulnerabilidade socioeconômica, para contribuir com suas despesas na participação em conferencias, congressos, cursos e outros eventos similares de cunho técnico, científico, cultural ou equivalente, dentro do país.

${ }^{12}$ É um espaço onde é oferecida alimentação para a comunidade universitária. Todos os acadêmicos de graduação presencial da UFMS - Cidade Universitária - podem realizar suas refeições no Restaurante Universitário com preços subsidiados. Preço do almoço: R $\$ 2,50$.

${ }^{13}$ José Brunner (2006, p. 3), em seu estudo sobre mercado universitário, aponta que está se produzindo ao redor do mundo um movimento que desloca o eixo de coordenação dos sistemas de educação superior do governo e das corporações acadêmicas - em geral, a esfera pública - para o mercado, isto é, para arranjos institucionais que forçam as universidades a competir entre elas por alunos, pessoal acadêmico e reputações, bem como a financiar suas atividades por meio de recursos obtidos - crescentemente de maneira competitiva - de uma diversidade de fontes fiscais e privadas. Este deslocamento é examinado na literatura anglo-saxônica sob o nome de marketization, que no castelhano traduz-se (em má tradução) por mercadização, ainda que se empreguem termos tais como privatização, comercialização e mercantilização.

${ }^{14}$ Imposto de Renda das Pessoas Jurídicas. Contribuição Social sobre o Lucro Líquido, instituída pela Lei n ${ }^{0} 7.689$, de 15 de dezembro de 1988. Contribuição Social para Financiamento da Seguridade Social, instituída pela Lei Complementar $n^{\circ} 70$, de 30 de dezembro de 1991. Contribuição para o Programa de Integração Social, instituída pela Lei Complementar $n^{\circ} 7$, de 7 de setembro de 1970.

${ }_{15}$ Extraído do documento Plano de Desenvolvimento Institucional (PDI) 2010-2014.

${ }^{16}$ Disponível em: <http://www.planalto.gov.br/ccivil_03/_Ato2007-2010/2010/Decreto/D7234.htm>. Acesso em: 22 out. 2015.

${ }^{17}$ Disponível em: <http://preae.sites.ufms.br/coordenadorias/assistencia/apoio-e-assistencia-academica/bolsapermanencia/>. Acesso em: 22 out. 2015. 


\section{REFERÊNCIAS}

AMARAL, Nelson Cardoso. Financiamento da educação superior: estado x mercado. São Paulo: Cortez; Piracicaba, SP: UNIMEP, 2003.

BORSATO, Francieli Piva. A configuração da assistência estudantil na Universidade Federal de Mato Grosso do Sul após a implantação do PNAES. 2015. Dissertação (Mestrado em Serviço Social e Política Social) - Universidade Estadual de Londrina, Londrina, 2015.

BRASIL. Ministério da Educação e Cultura. Gabinete do Ministro. Portaria Normativa no 39, de 12 de dezembro de 2007. Institui o Programa Nacional de Assistência Estudantil - PNAES. Portal MEC, Brasília, 2007. Disponível em: <http://portal.mec.gov.br/arquivos/pdf/portaria_pnaes.pdf>. Acesso em: 16 set. 2017.

Lei $\mathbf{n}^{0}$ 12.155, de 23 de dezembro de 2009. Dispõe sobre a concessão de Bônus Especial de Desempenho Institucional - BESP/DNIT aos servidores do Departamento Nacional de Infra-Estrutura de Transportes - DNIT; altera as Leis no11.171, de 2 de setembro de 2005, 10.997, de 15 de dezembro de 2004, 11.907, de 2 de fevereiro de 2009, e 11.507, de 20 de julho de 2007; e dá outras providências. Disponível em: <http://www.planalto.gov.br/ccivil_03/_ato2007-2010/2009/lei/L12155.htm>. Acesso em: 11 abr. 2017.

Decreto $\mathbf{n}^{\mathbf{0}}$ 7.416, de 30 de dezembro de 2010. Regulamenta os arts. 10 e 12 da Lei $\mathrm{n}^{\mathrm{o}} 12.155$, de 23 de dezembro de 2009, que tratam da concessão de bolsas para desenvolvimento de atividades de ensino e extensão universitária. Disponível em: <http://www.planalto.gov.br/ccivil_03/_ato20072010/2010/Decreto/D7416.htm>. Acesso em: 11 abr. 2017.

Ministério da Educação. Secretaria de Educação Superior. A democratização e expansão da educação superior no país (2003 a 2014). Brasília: MEC, 2015.

BRUNNER, José Joaquín. Mercados universitários: ideas, instrumentaciones y seis tesis en conclusión. Santiago, março de 2006. Disponível em: <http://www.brunner.cl/wpcontent/uploads/2012/12/\%C2\%A0MERCADOS-UNIVERSITARIOS_2006.pdf>. Acesso em: 31 jan. 2016.

CORDEIRO, Maria José de Jesus Alves; CORDEIRO, Ana Luisa Alves. Estratégias de permanência de estudantes na Universidade Estadual de Mato Grosso do Sul (UEMS). SEMINÁRIO DA REDE UNIVERSITAS/BR, 23. Belém/PA, 20 a 23 maio 2015. Anais... Belém: Universidade Federal do Pará, 2015. p. 831-851. Disponível em:

<http://www.obeduc.uerj.br/arquivos/AnaisRedeUniversitas2705.pdf>. Acesso em: 29 jan. 2016.

FÓRUM NACIONAL DE PRÓ-REITORES DE ASSUNTOS COMUNITÁRIOS E ESTUDANTIS (FONAPRACE). Perfil Socioeconômico e Cultural dos Estudantes de Graduação das Universidades Federais Brasileiras. Brasília, 2011.

Revista Comemorativa 25 Anos: histórias, memórias e múltiplos olhares. Fórum Nacional de Pró-reitores de Assuntos Comunitários e Estudantis. Uberlândia: UFU, 2012. 
HOFLING, Eloisa de Mattos. Estado e políticas (públicas) sociais. Caderno Cedes, ano XXI, nº 55, p. 30-41, nov. 2001. Disponível em: <http://scielo.br/pdf/ccedes/v21n55/5539>. Acesso em: 31 jan. 2016.

INSTITUTO NACIONAL DE ESTUDOS E PESQUISAS EDUCACIONAIS ANÍSIO TEIXEIRA (INEP). Sinopses Estatísticas da Educação Superior - Graduação (2013). Brasília, 2013. Disponível em: <http://portal.inep.gov.br/superior-censosuperior-sinopse>. Acesso em: 31 jul. 2015.

JANNUZZI, Paulo de Martino. Avaliação de programas sociais: conceitos e referenciais de quem a realiza. Est. Aval. Educ., São Paulo, v. 25, n. 58, p. 22-42, maio/ago. 2014.

JÚNIOR, João dos Reis Silva; SGUISSARDI, Valdemar. Forma e razões da expansão da educação superior pública no Brasil. In: MANCEBO; BITTAR; CHAVES. (Orgs.). Educação superior: expansão e reformas educativas. Maringá: Eduem, 2012. p. 21-42.

MENEZES, Simone Cazarin de. Assistência Estudantil na Educação Superior Pública: o programa de bolsas implementado pela Universidade Federal do Rio de Janeiro. 2012. 121f. Dissertação (Mestrado em Serviço Social) - Departamento de Serviço Social, Pontifícia Universidade Católica do Rio de Janeiro, Rio de Janeiro, 2012.

MANCEBO, Deise; BITTAR, Mariluce; CHAVES, Vera Lúcia Jacob. Educação superior, expansão e reformas educativas. In: MANCEBO; BITTAR; CHAVES. (Orgs.). Educação superior: expansão e reformas educativas. Maringá: Eduem, 2012. p. 13-19.

MACIEL, Carina Elisabeth et al. Acesso e permanência de estudantes na Universidade Federal de Mato Grosso do Sul: a expansão em questão. Relatório de Atividades, Campo Grande, 2015. p. 1-45.

MACIEL, Carina Elisabeth et al. Assistência Estudantil: a evolução de uma política pública e os significados no contexto da Educação Superior. In: SOUSA, José Vieira (Org.). Expansão e avaliação da educação superior brasileira: formatos, desafios e novas configurações. Brasília: Fino traço, 2015. p. 255-276.

RODRIGUES, José. Os empresários e a Educação Superior. Campinas, SP: Autores Associados, 2007 (Coleção polêmicas do nosso tempo).

SGUISSARDI, Valdemar. Estudo diagnóstico da política de expansão da (e acesso à) educação superior no Brasil 2002-2012. Brasília: Edital N. 051/2014 SESU; Projeto de Organismo Internacional - OEI; Projeto OEI/BRA/10/002, 2014.

SANTANA, Pamella Evangelista. Acesso e Permanência na UFMS: Os resultados obtidos nos formulários preenchidos pelos estudantes atendidos pela Ação Bolsa Permanência. 2015. Trabalho de Conclusão de Curso (Graduação em Pedagogia) - Universidade Federal do Mato Grosso do Sul, Campo Grande, 2015.

SILVA, Marcelo Soares Pereira da. Planejamento e Práticas da Gestão Escolar. Escola de gestores, [S.1], [201-?]. Curso de Especialização em Gestão Escolar. Disponível em: <http://escoladegestores.mec.gov.br/site/5-sala_planejamento_praticas_gestao_escolar/pdf/u1_1.pdf>. Acesso em: $1^{\circ}$ fev. 2016. 
SILVA, Maria das Graças Martins da; VELOSO, Tereza Christina Mertens Aguiar. Acesso à educação superior: significados e tendências em curso. Série-Estudo, Campo Grande, n. 30, p. 221-235, jul./dez. 2010.

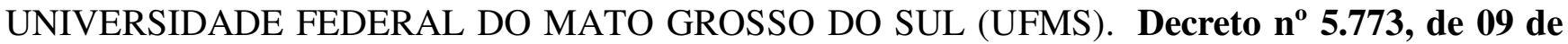
maio de 2006. Plano de Desenvolvimento Institucional 2015-2019. Campo Grande: UFMS, 2006. Disponível em: <http://www.pdi.ufms.br/>. Acesso em: 24 jul. 2015.

Plano de Desenvolvimento Institucional 2011-2014. Aprovado pela Resolução do Conselho Universitário $n^{\circ}$ 062/2010. Realinhamento aprovado pela Resolução do Conselho Universitário $\mathrm{n}^{\circ}$ 085/2011. Campo Grande: UFMS, 2011. Disponível em: <http://www.pdi.ufms.br/manager/titan.php?target=openFile\&fileId=497>. Acesso em: 28 ago. 2015.

Pró-Reitoria de Extensão, Cultura e Esporte. Conselho Universitário. Resolução n⿳0 7 de 6 de fevereiro de 2014. Campo Grande: UFMS, 2014a. Disponível em: $<$ http://preae.sites.ufms.br/coordenadorias/assistencia/apoio-e-assistencia-academica/bolsapermanencia/>. Acesso em: 11 set. 2015.

. Pró-Reitoria de Planejamento e Orçamento. Coordenadoria de Planejamento Institucional. Divisão de Acompanhamento e Avaliação. Relatório de Avaliação do PDI 2010-2014. Ano base 2013. Campo Grande: UFMS, 2014b. Disponível em: < https://proplan.ufms.br/2016/08/01/relatoriode-avaliacao-pdi-2015-2019/>. Acesso em: 18 set. 2017.

Pró-Reitoria de Extensão, Cultura e Esporte. Conselho Universitário. Resolução no 7, de 6 de fevereiro de 2015. Campo Grande: UFMS, 2015a. Disponível em: $<$ http://preae.sites.ufms.br/coordenadorias/assistencia/apoio-e-assistencia-academica/bolsapermanencia/>. Acesso em: 11 abr. 2017.

Pró-Reitoria de Planejamento e Orçamento. Coordenadoria de Planejamento Institucional. Divisão de Acompanhamento e Avaliação. Relatório de Avaliação do PDI 2010-2014. Ano base 2014. Campo Grande: UFMS, 2015b. Disponível em: <https://proplan.ufms.br/2016/08/01/relatoriode-avaliacao-pdi-2015-2019/>. Acesso em: 18 set. 2017.

VIEIRA, Evaldo. Os direitos e a política social. 3. ed. São Paulo: Cortez, 2009. 
The permanency scholarship in politics of University education: student assistant at UFMS

Abstract

This current study aims to identify the Student Assistance policy, at Universidade Federal de Mato Grosso do Sul/UFMS, Campo Grande/MS campus, through the Pedagogical Support Programs and Financial offered to students, considering that the "Permanency Scholarship" consists of the scholarship student stability strategy in that institution. The research is exploratory, bibliographic and documentary character, presenting as sources reports and institutional documents. For this, we base ourselves on the following theoretical contributions: Sguissardi (2014); Maciel (2015); Mancebo, Bittar and Chaves (2012); Hofling (2016) and Borsato (2015). They are presented and analyzed quantitative and qualitative data. The text is the result of part of research funded through of the Edital FUNDECT / CNPq No. 14/2014 - PPP - MS. The first approaches led us to identify that the university in question has pedagogical and financial support programs, but not all students meet the selectivity criteria imposed by each of the areas: health, nutrition, monitoring scholarship, permanence and student mobility. That is, the university is dualized between its projects and actions covering only part of these students. It concludes that the action Exchange Permanence has changed in its selection criteria and that there is a high rate of unfilled vacancies, requiring a review of the monitoring policy of selected and non-selected academic of the action.

Key words: University education. Permanency. Student assistant.

\section{La beca de permanencia en las políticas de educación superior: la asistencia al estudiante en la UFMS}

\section{Resumen}

Este estudio tiene como objetivo identificar la política de Asistencia al Estudiante, en la Universidade Federal de Mato Grosso do Sul/UFMS, campus Campo Grande/MS, a través de Programas de Apoyo Pedagógico y Financiero ofrecidos a los estudiantes, dado que la "Beca de Permanencia" consiste en una estrategia de estabilidad para el alumno becario en la institución mencionada. La investigación es de carácter exploratorio, bibliográfico y documental, donde informes y documentos institucionales son presentados como fuente de información. Por lo tanto, nos embasamo en las siguientes contribuciones teóricas: Sguissardi (2014); Maciel (2015); Mancebo, Bittar y Chaves (2012); Hofling (2016) y Borsato (2015).

Son presentados $\mathrm{y}$ analizados datos cuantitativos y cualitativos. El manuscrito es resultado de una parte de la investigación financiada por medio del Comunicado FUNDECT/CNPq N ${ }^{\circ}$ 14/2014 - PPP - MS. Los primeros acercamientos condujeron a identificar que la universidad estudiada posee programas de apoyo pedagógico y financiero, pero que no todos los alumnos(as) están insertos en los criterios de selección otorgados por cada una de las áreas: salud, alimentación, becas de ayudantía, permanencia y movilidad del estudiante. Es decir, la universidad se encuentra polarizada entre sus proyectos y acciones que incluyen solamente a parte de estos estudiantes. Se concluye que la Beca de Permanencia sufrió cambios en sus criterios de selección y que existe un alto índice de vacantes sin cubrir, de modo que se torna necesaria una revisión de la política de acompañamiento de los alumnos seleccionados y no seleccionados por el programa.

Palabras-clave: Educación superior. Permanencia. Asistencia estudiantil. 


\section{Carina Elisabeth Maciel}

E-mail: carina22em@gmail.com

\section{Felipe Vieira Gimenez}

E-mail: felippegimenezz@gmail.com

Jacira Helena do Valle Pereira Assis

E-mail: jpereira.dou@terra.com.br
Enviado em: 26/04/2016

Versão final recebida em: 17/04/2017

Aprovado em: 24/04/2017 